\title{
Experimental determination of deflagration explosion characteristics of methane-air mixture and their verification by advanced numerical simulation
}

\author{
M. Mynarz, P. Lepík \& J. Serafin \\ Faculty of Safety Engineering, VSB-Technical University of Ostrava, \\ Czech Republic
}

\begin{abstract}
Venting is a widely applied method to protect buildings and technological equipment from effects of internal explosion. The key problem in venting is the adequate design of vent area and an effective material of venting element. A set of 76 experiments on partly confined methane-air mixture explosions with various parameters was processed. In terms of experiments, vent areas and venting elements with variable values of static activation pressure were changed. During measurements, certain items were determined at steady stoichiometric mixture concentration and atmospheric conditions: reduced explosion pressures, rates of reduced explosion pressures rise, temperatures, flame lengths and deformations of experimental equipment enclosure. Together with experiments, modelling of these processes was carried out by the codes based on computer fluid dynamic (CFD) using numerical tool FLACS (Flame Acceleration Simulator). Results of experiments and CFD models are analysed and compared to each other.

Keywords: deflagration, venting, explosion characteristics, numerical simulations.
\end{abstract}

\section{Introduction}

Venting of deflagration belongs to the group of construction arrangements for explosion protection. This arrangement for explosion protection itself will not prevent an explosion; instead it is ensured that its dangerous effects are limited to 
a tolerable level. If you cannot therefore prevent a hazardous explosive atmosphere and eliminate the risk of explosion by active arrangements of explosion prevention, or if such arrangements are inadequate, the equipment shall be designed to limit the effects of an explosion to a safe level. Arrangements will therefore ensure that no damage or danger to persons occur, and after a short time the equipment is again able to run. For this purpose the device is fitted with one or more venting elements. These venting elements are closed devices, which will open in case of an explosion and increasing pressure on the static activation pressure of venting element, which is significantly lower than the maximum explosion pressure. Due to venting of the chamber, burnt and unburned products of explosion can flow out. The pressure inside the vessel has reached only a fraction of the maximum explosion pressure.

The time-pressure curve at partly-venting deflagrations and the values of explosion pressure and rate of explosion pressure rise $(\mathrm{dp} / \mathrm{dt})$ change significantly with the size of vent area and with value of static activation pressure of venting elements. The highest values of explosion pressure and rate of explosion pressure rise are reached at the optimal concentration of $\mathrm{C}_{\mathrm{opt}}$, which is very close to the stoichiometric concentration. In the case of venting explosions, these values are called the maximum reduced explosion pressure and the maximum rate of explosion pressure rise $(\mathrm{dp} / \mathrm{dt})_{\text {red,max }}$. The course of explosion and maximum explosion parameters are affected by many factors, including the size and shape of the chamber, the concentration of explosive mixture, initial pressure and initial temperature, ignition energy, the location of ignition source, turbulence of a mixture, the oxygen content in the atmosphere and others (Mračková [4]).

\section{Experimental}

Figure 1 shows a schematic diagram of test equipment. This device consists of a detonation chamber in the shape of a cube with edge length of $650 \mathrm{~mm}$. Total volume of the device is $\mathrm{V}=250 \mathrm{dm}^{3}$.

A mixer as a part of the test device is used to homogenization of investigated explosive mixture. It consists of a high speed electric motor with a clarifying propeller powered by low voltage. Ignition is performed using the pin with intermittent with initial energy of $86 \mathrm{~J}$ and it is also powered by low voltage. The explosive mixture is prepared in the chamber through the inlet valves. The concentration of compound is detected using gas detection equipment (EXMETER II) at several points in the chamber (ČSN EN 14797 [1]).

The reduced explosion pressure had been measured by high pressure transducer for dynamic pressure (KISTLER 701A) with a natural frequency response of $70 \mathrm{kHz}$. The signal from pressure transducer was through charge amplifier and $\mathrm{A} / \mathrm{D}$ converter recorded by the computer. The temperature was scanned over the temperature sensor and by digital thermometer (GMH GREISINGER 3250) it was also recorded by the computer. Digital sensor of transfer with an accuracy of $0.01 \mathrm{~mm}$ was located in the middle of the top part 


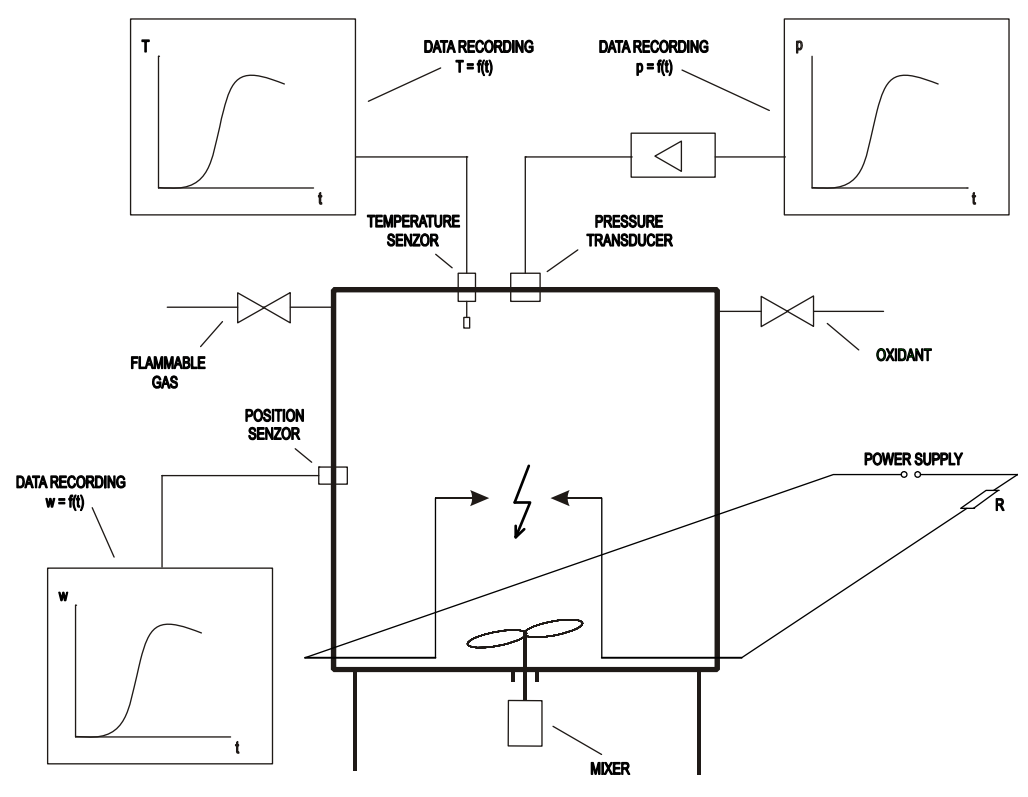

Figure 1: Schematic diagram of the experimental setup.

for sensing of response of the chamber envelope. The course of explosion and flame length was scanned with a digital camera (PANASONIC DMC-LZ10).

\subsection{The measurement procedure}

The actual measurement consisted of three specific parts, within which specified tasks were carried out. In the first phase, the set of venting diaphragms based on waxed paper, aluminium foil, polyethylene foil and sealing panels made of organic fibres of different thicknesses was produced. Thickness and specific weights of individual venting diaphragms are listed in Table 1.

Table 1: Thickness and specific weights of venting diaphragms used in the measurement.

\begin{tabular}{lcc}
\hline Diaphragm Material & $\begin{array}{c}\text { Thickness } \\
(\mathbf{m m})\end{array}$ & $\begin{array}{c}\text { Specific weights } \\
\left(\mathbf{k g . \mathbf { m } ^ { - 2 }}\right)\end{array}$ \\
\hline Waxed paper & 0,05 & 0,041 \\
\hline Waxed paper & 0,06 & 0,092 \\
\hline Aluminium foil & 0,05 & 0,134 \\
\hline Polyethylene foil & 0,12 & 0,035 \\
\hline Polyethylene foil & 0,20 & 0,170 \\
\hline Sealing panel & 0,50 & 1,034 \\
\hline Sealing panel & 1,00 & 1,830 \\
\hline
\end{tabular}


With the exception of sealing panels, other materials are the diaphragms, which are almost without inertia moment and do not slow down the venting process. Venting diaphragms were gradually installed by mounting flange to the opening in chamber envelope.

For the measurements, three sizes of square openings were used with dimensions of $140 \times 140 \mathrm{~mm}\left(0,02 \mathrm{~m}^{2}\right), 200 \times 200 \mathrm{~mm}\left(0,04 \mathrm{~m}^{2}\right)$ and $345 \times 345$ $\mathrm{mm}\left(0,12 \mathrm{~m}^{2}\right)$. Openings occupy 5,10 and $30 \%$ of one wall of the chamber envelope. To determine the value of the static activation pressure of diaphragms according to (ČSN EN 14994 [2]), five measurements were made and the average values are given in Table 2. Measurements were carried out at atmospheric pressure $\mathrm{P}_{\mathrm{atm}}=0,961$ bar and ambient temperature $\mathrm{T}_{\mathrm{i}}=14^{\circ} \mathrm{C}$.

Table 2: $\quad$ Values of the average static activation pressures (bar g).

\begin{tabular}{lccc}
\hline $\begin{array}{l}\text { Material and thickness of } \\
\text { diaphragm }(\mathbf{m m})\end{array}$ & 0,02 & 0,04 & 0,12 \\
\hline Waxed paper 0.05 & 0,163 & 0,080 & - \\
\hline Waxed paper 0.06 & 0,318 & 0,226 & 0,080 \\
\hline Aluminium foil 0.05 & 0,226 & 0,136 & - \\
\hline Polyethylene foil 0.12 & 0,261 & 0,187 & - \\
\hline Polyethylene foil 0.20 & 0,330 & 0,229 & 0,136 \\
\hline Sealing panel 0.50 & 0,282 & 0,211 & 0,083 \\
\hline Sealing panel 1.00 & 0,449 & 0,339 & 0,139 \\
\hline
\end{tabular}

The second stage was the preparation of an explosive mixture in the device. As a flammable gas to create an explosive mixture, methane $\left(\mathrm{CH}_{4}\right)$ was chosen. It is the most common and simplest alkane and thus the simplest hydrocarbon in general. After homogenizing of the mixture of methane with air, a delay follows to calm the flow in the chamber so that air mass turbulence is close to zero. In the chamber, there were no obstacles that would cause an increase of turbulence. The third phase involves the ignition of the mixture (in the centre of the chamber) and recording all monitored parameters.

\subsection{Models in FLACS code}

FLACS is a computational fluid dynamics (CFD) code solving the compressible conservation equations on a $3 \mathrm{D}$ Cartesian grid using a finite volume method. The conservation equations for mass, momentum, enthalpy, and mass fraction of species, closed by ideal gas law, are included. The conservation equations can be represented in general as:

$$
\frac{\partial}{\partial t}(\rho \Phi)+\frac{\partial}{\partial x_{j}}(\rho u \Phi)-\frac{\partial}{\partial x_{j}}\left(\rho \Gamma \Phi \frac{\partial}{\partial x_{j}}(\Phi)\right)=S_{\phi}
$$

The numerical model uses a second order scheme for resolving diffusive fluxes and a second order $\kappa$ scheme to resolve the convective fluxes (FLACS [3]). 
According to geometry of the experimental chamber, CFD numerical model was created to verify the modelling of explosion processes. All parameters of the model were configured to correspond truly to the executed experiments (Mynarz and Šimoník [5]). The total number of control volumes of the model was defined as 924992. The control volumes were of different sizes. The smallest sizes of control volumes were modelled in the equipment area including space in front of the opening. With increasing distance in all directions of axes of the coordinate system, their sizes increased. Dimensions of control volumes ranged from 0,03 to $0,54 \mathrm{~m}$. The walls of the device were modelled as a solid with porosity of 0,0 and the diaphragm in the openings as explosion relief panels. After checkout of the model, very time-consuming simulations were performed.

\section{Results and discussion}

Experiments were performed on the above-described device at atmospheric pressure $\mathrm{P}_{\mathrm{atm}}=0,995$ bar and temperature inside the chamber $\mathrm{T}_{\mathrm{i}}=12^{\circ} \mathrm{C}$. For each diaphragm type and size of venting diaphragm, four measurements were performed. Measurements were carried out with stoichiometric mixture concentration $(9,5 \%)$. At several openings of area $0,12 \mathrm{~m}^{2}$ measurements were not performed. Within the experiments, several parameters of explosion were monitored. The most interesting parameter was reduced explosion pressure $p_{\text {red. }}$. Figure 2 shows the course of this pressure as a function of time.

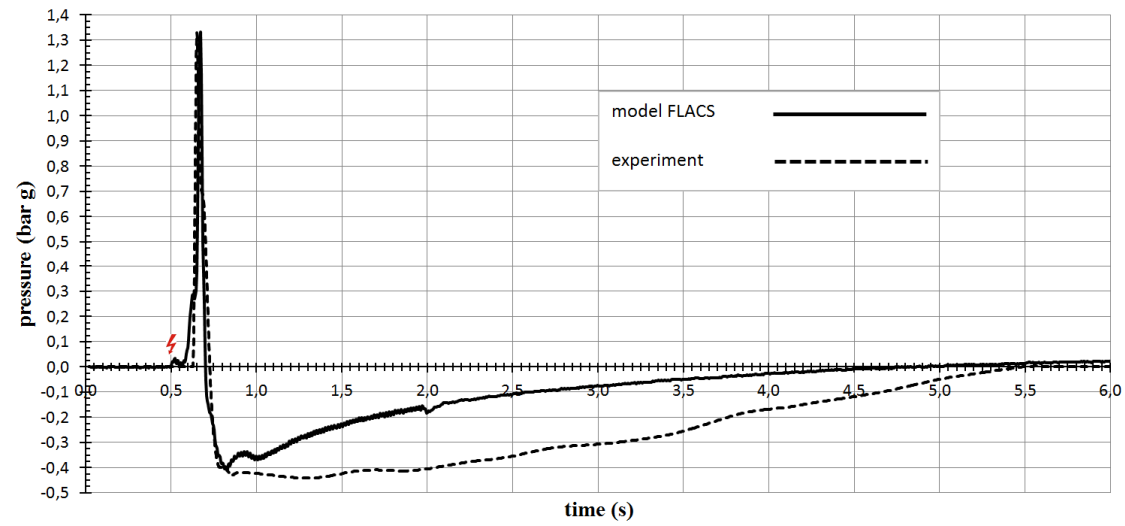

Figure 2: The courses of explosions from the experiment and the numerical model.

It is the comparison of measured and computed reduced explosion pressures where vent area was $0,04 \mathrm{~m}^{2}$ and the diaphragm on the base of waxed paper $0,06 \mathrm{~mm}$ was used. In comparison with the numerical model, very good agreement has been achieved in this case.

Final values of explosion pressures were measured at monitoring point in the middle of the top part of the chamber envelope. During experiment, the pressure 
were scanned from the same point. Figures 3 and 4 present the comparison of the experiment explosion course and the course calculated using numerical model. The comparison was made for the vent area of $0,02 \mathrm{~m}^{2}$ and for various values of static activation pressure (see Table 2). The curves become more distant in a negative phase but duration of the pressure compensation is very similar.

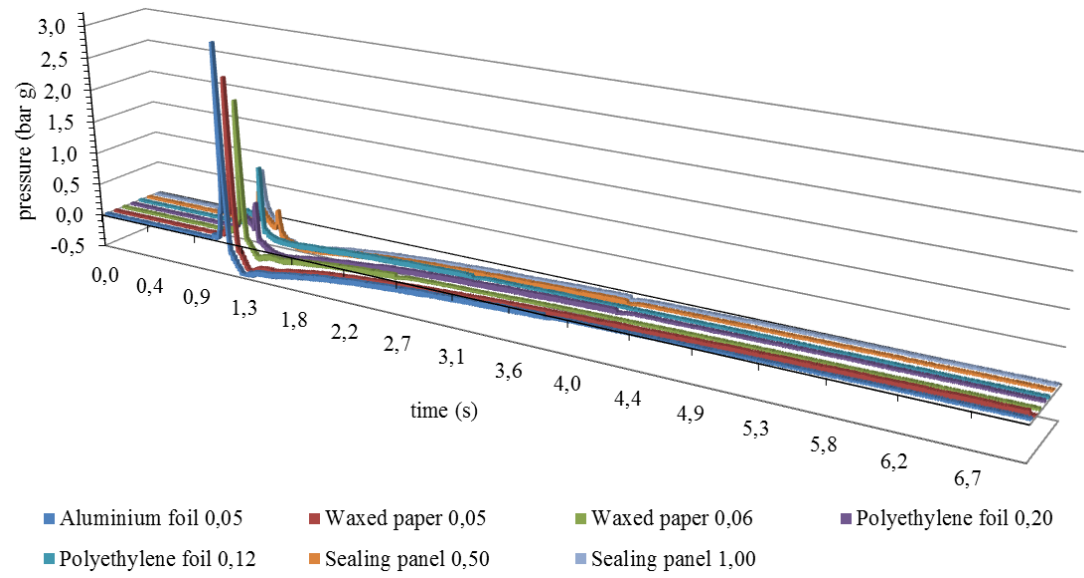

Figure 3: The courses of explosions obtained from the experiment at the vent area of $0,02 \mathrm{~m}^{2}$.

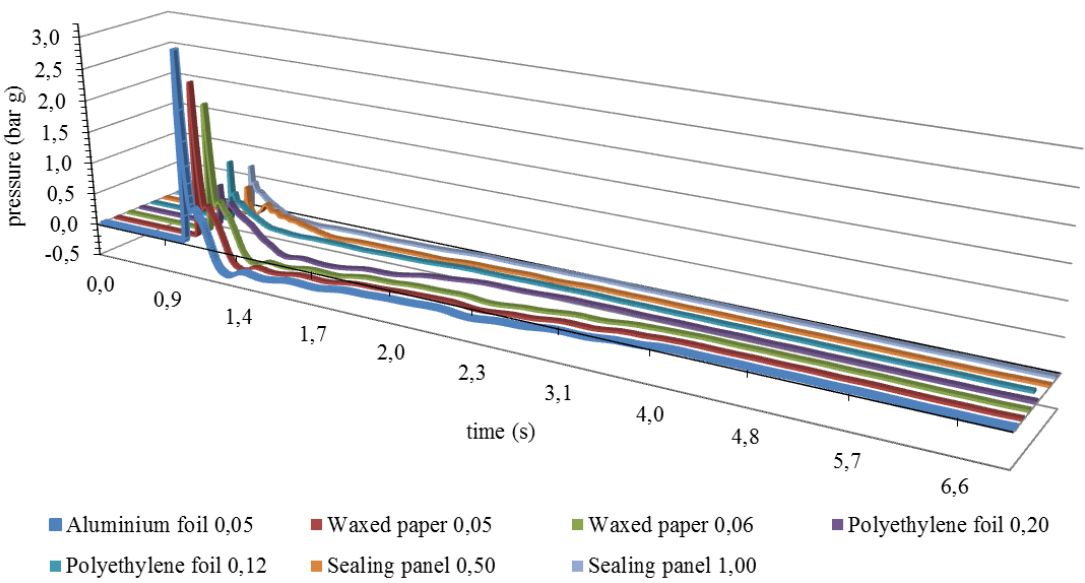

Figure 4: The courses of explosions obtained from the calculation at the vent area of $0,02 \mathrm{~m}^{2}$.

The comparison for the vent area of $0,04 \mathrm{~m}^{2}$ and for various values of static activation pressure is represented by graphs in Figures 5 and 6. 


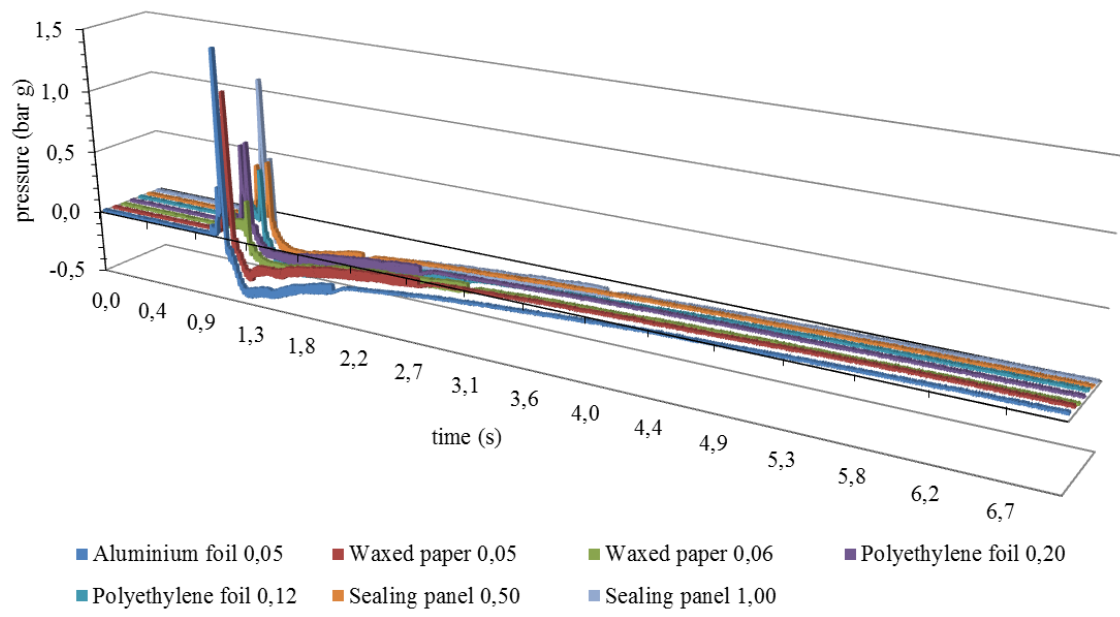

Figure 5: The courses of explosions obtained from the experiment at the vent area of $0,04 \mathrm{~m}^{2}$.

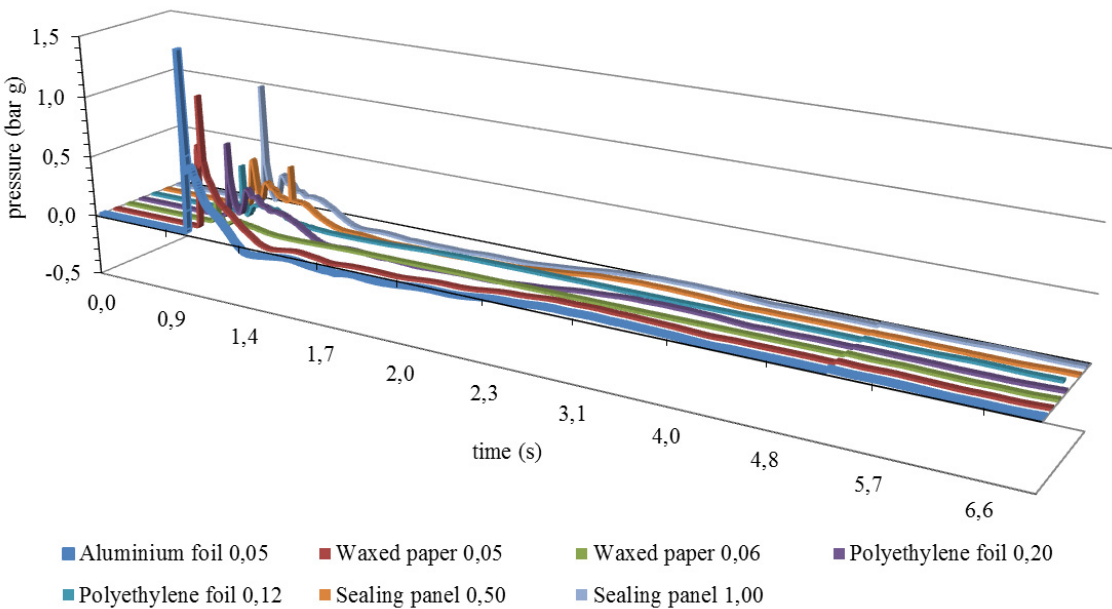

Figure 6: The courses of explosions obtained from the calculation at the vent area of $0,04 \mathrm{~m}^{2}$.

Figures 7 and 8 again show the courses of explosion, but the vent area is $0,12 \mathrm{~m}^{2}$. In the case of the courses of explosions obtained from the experiment, significant oscillations are obvious, especially in the negative phase of the explosion. Also, the coincidence of values of the reduced explosion pressures is less. 


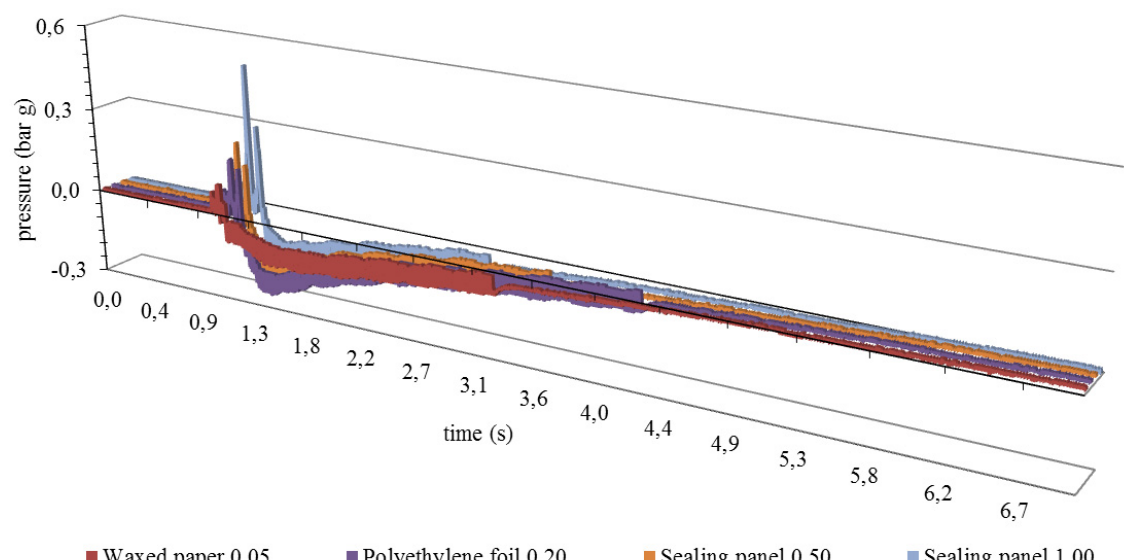

Figure 7: The courses of explosions obtained from the experiment at the vent area of $0,12 \mathrm{~m}^{2}$.

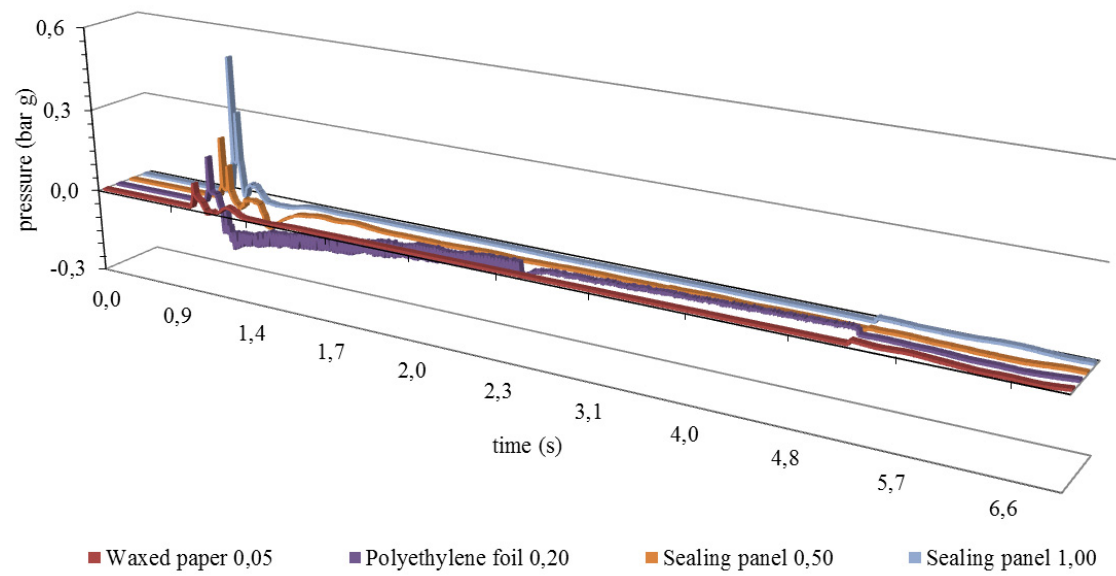

Figure 8: The courses of explosions obtained from the calculation at the vent area of $0,12 \mathrm{~m}^{2}$.

The following figures correspond to the initial conditions of the simulation and to the explosion course shown in Figure 2. At the time of $0.12 \mathrm{~s}$ (measured from the ignition), the vent area was opened (ruptured) and the products of combustion (flame) are eliminated from the experimental device through the opening out into the environment (see Figure 9). Relative concentration of combustion products is shown in the scale next to the graph.

Figure 10 illustrates the course of combustion products in time of 2,5 s when the simulation of the explosion was finished. 


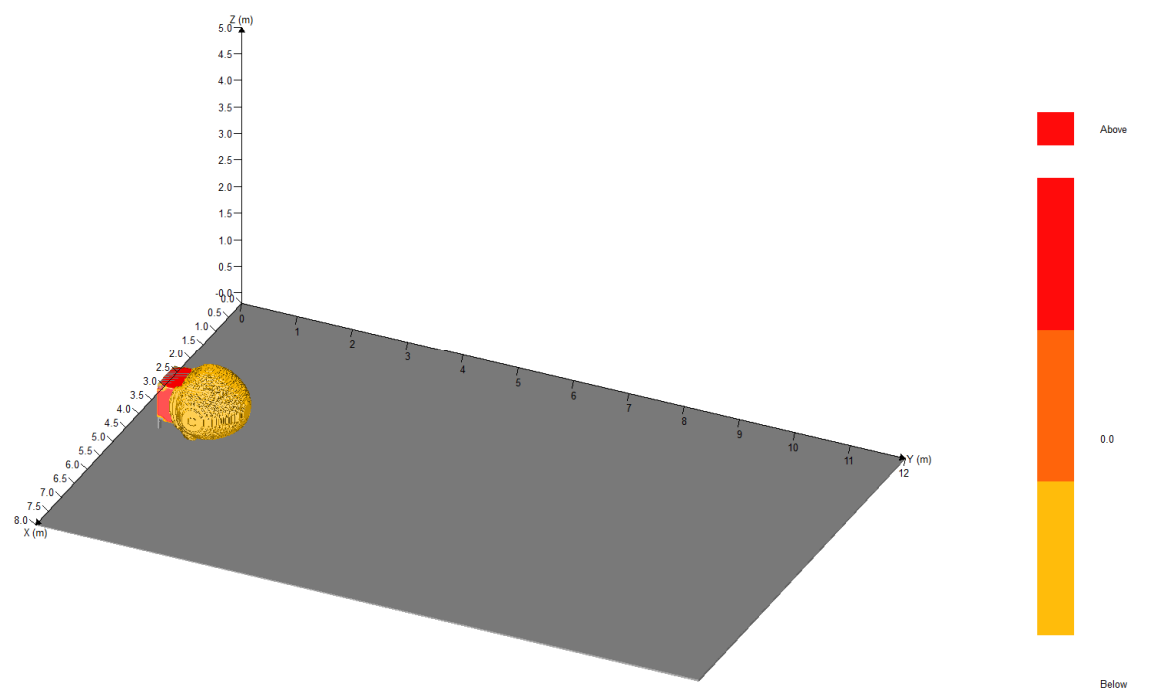

Figure 9: The course of products of combustion in time of $0,12 \mathrm{~s}$.
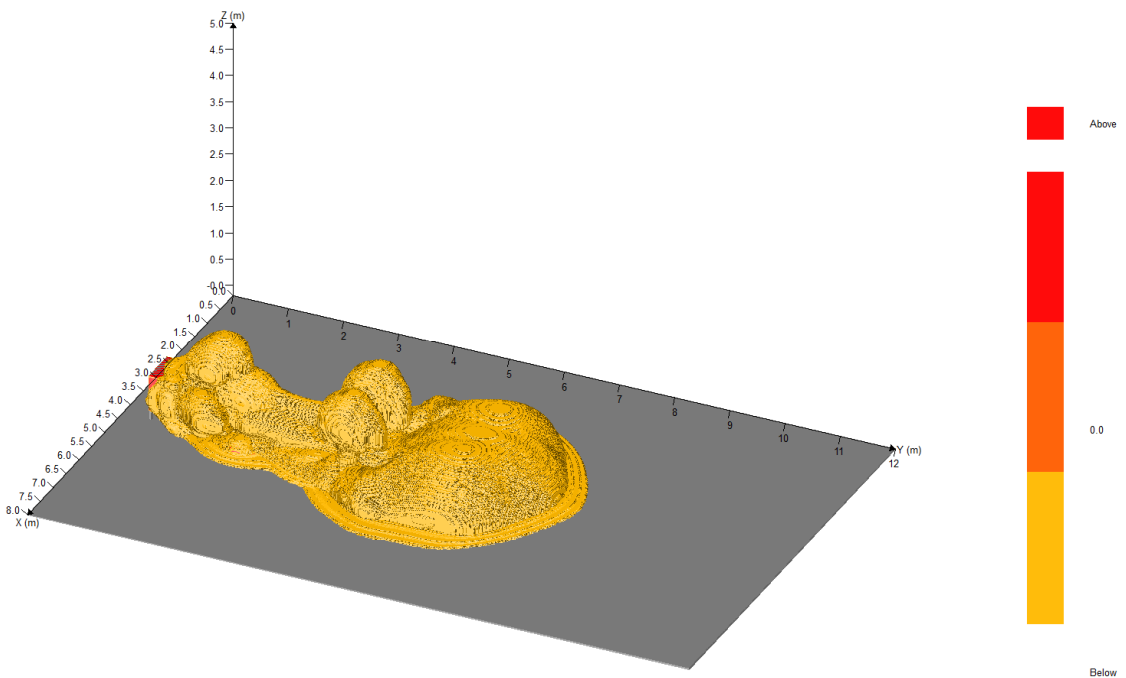

Figure 10: The course of products of combustion in time of 2,5 s.

\section{Conclusions}

The size of the maximum reduced pressure depends on the timeliness of venting elements opening, i.e. the static activation pressure $p_{\text {stat }}$, and on the size of the vent area. The higher pressure $p_{\text {stat }}$, the greater the volume of explosive mixture 
reacts until the moment of vessel venting, and thus will also be a higher maximum reduced pressure $p_{\text {red,max }}$. With the increasing size of the vent areas, the effectiveness of cumulative pressure taking out increases and maximum reduced pressure $\mathrm{p}_{\text {red,max }}$ is then lower.

Static activation pressure $p_{\text {stat }}$ of venting device is suitable to choose the lowest. However, the condition must be met that the static activation pressure $\mathrm{p}_{\text {stat }}$ must be higher than the working pressure in the device to prevent cracking of the diaphragms and accidental opening of the device.

By comparing the courses of explosions obtained from the experiment and from the calculation using the numerical model, very good agreement can be observed. The models according to FLACS code embody more gentle stabilization of pressures in negative phase. However, the duration of the negative pressure phase is very similar. For the vent area of $0,12 \mathrm{~m}^{2}$, the differences occurred at the courses of explosions obtained from experiment and from calculation (mainly in the negative phase). The differences in the reduced explosion pressures are about $30 \%$. The measurements and simulations have confirmed again that the explosion parameters of partly confined explosions are, among other factors, heavily dependent on the size of the opening and on the static activation pressure of venting elements.

\section{Acknowledgement}

The contribution was written as a part of a project of a student grant competition (SP2012/116) "Determination of parameters of generated blast waves of venting explosions”.

\section{References}

[1] ČSN EN 14797, Explosion venting devices (in Czech), Prague, ČNI, 2007.

[2] ČSN EN 14994, Gas explosion venting protective systems (in Czech), Prague, ČNI, 2007.

[3] FLACS v9.1, User's Manual, Norway, GexCon AS, 2010.

[4] Mračková, E., Explosion protection for the transportation of natural gas (in Slovak). Proc. of the $15^{\text {th }}$ Int. Conf. On Fire protection 2006, eds. M. Šenovský, SPBI: Ostrava, pp. 245-255, 2006.

[5] Mynarz, M., Šimoník, Z., Assessment Methods for Explosion Load Parameters of Chosen Building Structure (in Czech). Spektrum, 10(2), pp. 24-26, 2010. 